\title{
Network Temperatures and Flow Rate: Case Study of District Heating in Canberra, Australia
}

\author{
Stanislav Viktorovich Chicherin \\ Thermal Engineering Department, Omsk State Transport University, Omsk, Russia
}

Email address:

man_csv@hotmail.com

\section{To cite this article:}

Stanislav Viktorovich Chicherin. Network Temperatures and Flow Rate: Case Study of District Heating in Canberra, Australia. International Journal of Energy and Environmental Science. Vol. 3, No. 3, 2018, pp. 61-68. doi: 10.11648/j.ijees.20180303.12

Received: July 6, 2018; Accepted: July 16, 2018; Published: August 9, 2018

\begin{abstract}
The purpose of this paper is to highlight the relevance of district heating (DH) in the country where, in general, there is no such system and, specifically, to develop and implement a helpful approach for designing a DH network combining thermal and hydraulic considerations to simulate the energy behaviour of such network. The nonlinear model of the supply and return temperatures describes the dynamics of a DH system with an appropriate accuracy. The results of the generated scenarios are partial load values obtained for each category. The data on the daily heating power demand was transformed into an outdoor temperature dependence curve used to compute the flow rate for each of the scenario. Under the designed condition, the flow is determined and regulation approaches are elaborated. The resulting flow is quite stable. Taking into account the deficiencies of conventional evaluation for DH networks, this study excludes the hypothesis of constant outdoor temperature, and analyzes the influence of outside temperature on the heat losses and electricity consumption for DH networks based upon the state-space method. The obtained results are achieved without significant investments into a DH system just by adjusting and controlling temperatures and flow rates of a heat radiator circulating in the network.
\end{abstract}

Keywords: Demand, Flow, Thermal, Weather

\section{Introduction}

A district heating (DH) network offers the opportunity to satisfy the collective heat demand of a cluster of geographically concentrated buildings through a set of central heat sources. This allows for the use of centralized production techniques with an efficiency exceeding that of distributed production (stand-alone, individual) [1]. Therefore, a correct DH design as a critical part of a city's energy development strategy can lead to great economic and environmental benefits, contributing significantly to the development of low-carbon cities [2].

To justify the original nature of the manuscript, the section includes the most relevant $R \& D$ references selected for a literature survey.

Delangle et al. [3] carried out a thorough literature survey of the articles on optimizing the existing DH network published in a range of top energy journals for the last four years. All controllers, discussed in [4], use optimization methods to determine the actions in a DH network. To fully evaluate the latest findings and key challenges relating to the topic of a $\mathrm{DH}$ network modelling, one can address the paper by del Hoyo Arce [5].

The nonlinear model of a plate heat exchanger described by Wang et al. [6] was simulated in Simulink. A heat load forecast model, based on the HIRLAM numerical weather prediction model and provided by the Danish Meteorological Institute, was used in [7].

The instantaneous mass flow rate depends on the heat capacity of a system and a design (maximum) value that was assigned to a selected unit as shown in [8]. The mass flow is almost always steady or quasi-steady as well, except for very short transients when it changes and then settles with the speed of sound [9]. In the paper [10] the authors refer to a "bidirectional distribution" system as the one where water in each pipe segment can flow in alternating directions depending on the net thermal fluxes in the system. The mass flow is in contrast with the heat flow spatio-temporal evolution within a DH network as it is never steady. A novel feature in [11] is the integration of hydraulic considerations into all components involved into the supply temperature optimization process. 
Babiarz \& Blokus-Roszkowska [12] express temperature variation within a year by means of a thermal load factor. In future, energy systems could be designed in a more flexible way to incorporate fluctuations in demand and therefore allow using distributed renewable energy sources located in various points [13]. Valincius et al. [14] assessed the failure reliability of DH networks using the method integrated with the thermal-hydraulic analysis.

In Ref. [15] certain variables enable evaluating the change in reliability of $\mathrm{DH}$ networks due to changeable outdoor temperature during the heating time. During the project [16] a modified device was added to this existing controller hardware which makes it possible to interact with this device remotely through an outside temperature sensor override mechanism. This makes it possible to control the substation by sending alternative outside temperature signals to the input; the underlying controller will then respond to this signal according to its default settings.

The poor-quality of utilities in Russia [17] causes the need to repeat excavation and reinstatement over their lifetime (up to 25 years) and therefore adds many long-term costs relating to sustainability (depreciation) costs.

It has already been shown that a conventional radiator system in the existing building without any renovation done can ensure a comfortable indoor climate with a supply temperature of 45C [18]. In Ref. [19], Hyllie's (area under construction in the southern part of Malmö, Sweden) buildings were supposed to have floor and wall heating systems needing a supply temperature of only 30C. Aghdaei et al. [20] show an example of simulation designs for various building types and provide a summary of the design order plan for calculating total energy consumption of a dwelling in Australia.

When interpreting the results obtained, it should be kept in mind that they are typically based on a case study. For instance, in Ref. [21] a particular district was chosen due to the fact that it is mostly residential, and it consists of buildings that can be considered as the reference ones for the French building stock. The heating plant and the DH network of the University of Liège, Belgium, with an effective peak power of $56 \mathrm{MW}$ and a total heat demand of around $61 \mathrm{GWh}$ are used as an application test case in [22].

One of the Hou's options [2] does not consider energy conservation and secondary load structure improvement, and heating and cooling load of new buildings are all supported by electric air-conditioners. In Ref. [23] the annual water volumes decrease with improved building thermal performances. The results in [24] indicate that there is no obvious correlation between the amount of generated electricity and the profit received from electricity sales in the investigated scenarios. The higher the actual heat production of a unit, the higher its thermal efficiency is as indicated by Coss et al. [25]. If the capacity of the total production plants is lower than the peak demand, thermal energy storages are necessary [26]. However, in Tianjin Eco-City, China, the actual load of the energy station, which has been in operation for four years, is still less than the design load, and the peak load value is only $25 \%$ of the design load [27]. In order to alleviate the fluctuation and enhance energy performance, thermal storage devices are often applied along with a renewable source [28].

The knowledge gap can be formulated as follows 'How should this new heating technology be designed and when is it feasible to phase out old technology?' [29] in a country where DH has never been widely used on the heat market. On the contrary, e.g., in Mediterranean regions the major problem of a DH system management is the presence of a peak demands, particularly, in the mornings [30].

The aim of this article is to highlight the relevance of $\mathrm{DH}$ in a country, which, in general, does not have one and, specifically, to develop and implement a helpful approach for design of a DH network combining thermal and hydraulic considerations to simulate the energy and physical behaviour of the analysed network.

\section{Materials and Methods}

If the network pressure is below 1.0 MPa, a simpler direct consumer connection can be used. A diagram of a substation configuration is supplied in Figure 1.

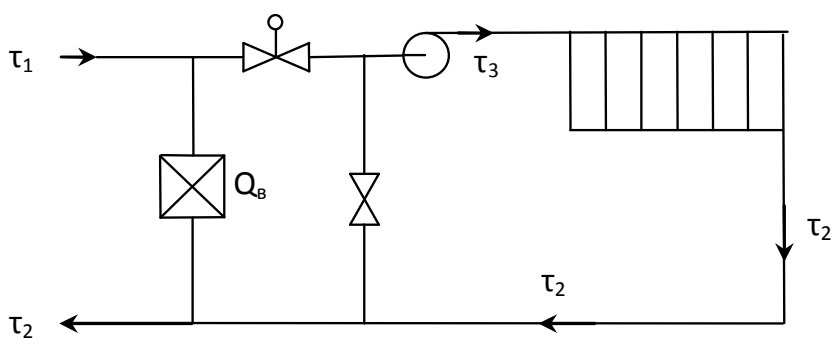

Figure 1. Direct connection layout.

The direct connection has no heat exchanger for the space heating system. There are many disadvantages of implementing direct systems, for instance, a lack of separation of the DH network and the building utilities, no possibility of a DH network operation on the pressure levels independent on the building installations, which can be especially crucial in hilly locations. Its major benefits include a lower price and conservative maintenance. The nonlinear ordinary equation model of supply $\tau_{1}$ and return $\tau_{2}$ temperatures was derived:

$$
\begin{gathered}
\tau_{1}=t_{i}+M T D \cdot \bar{Q}_{0}^{0,8}+\left(\delta \tau-\frac{\Theta}{2}\right) \cdot \bar{Q}_{0}, \\
\tau_{2}=t_{i}+M T D \cdot \bar{Q}_{0}^{0,8}-\frac{\Theta}{2} \cdot \bar{Q}_{0},
\end{gathered}
$$

where $t_{i}$-desired indoor temperature, ${ }^{\circ} \mathrm{C}$;

MTD - mean temperature difference between temperature of indoor air and a radiator's surface, ${ }^{\circ} \mathrm{C}$ :

$$
M T D=\frac{\tau_{3}+\tau_{2}}{2}-t_{i},
$$


Relative thermal power output from a $\mathrm{DH}$ system $\bar{Q}_{0}$, $\mathrm{MW}$, is expressed as follows:

$$
\bar{Q}_{0}=\frac{Q_{0 c}}{Q_{0}}=\frac{t_{i}-t_{H}}{t_{i}-D O T},
$$

where $Q_{0 c}$ - current heat load, MW;

$Q_{0}$ - design heat load, MW;

$t_{c}$ - current outdoor temperature, ${ }^{\circ} \mathrm{C}$;

DOT - design outdoor temperature, ${ }^{\circ} \mathrm{C}$.

A temperature difference in a radiator system $\Theta_{p},{ }^{\circ} \mathrm{C}$, can be determined as described in Eq. 5:

$$
\Theta=\tau_{3}-\tau_{2},
$$

Design supply-return temperature difference $\delta \tau_{p},{ }^{\circ} \mathrm{C}$ :

$$
\delta \tau=\tau_{1}-\tau_{2}
$$

DH system parameters including the boundary conditions of indoor and radiator temperatures and load rates given in Ref. [31] have been used to validate the proposed nonlinear model described by Eqs. (1) and (2). A nonlinear model was validated using the measured data and actual operation parameters given in Ref. [32]. To assess model performance, the mean absolute percentage error given by Eq. (7) and provided by Dahl et al. [7] was selected.

$$
M A P E=\frac{1}{n} \sum_{i}\left|\frac{T_{i}-\tau_{1 i}}{\max \left(T_{i}, \tau_{1 i}\right)}\right| \text {, }
$$

Where $T_{i}$ is a scheduled supply temperature and $\mathrm{i}$ is a number of validating points.

We referenced to daily extreme temperatures on the site registered to date using non-linear regressions.

Six model runs were performed with the same input data as for the three default scenarios.

Firstly, default scenarios relate to profile temperatures that can be chosen among the following values: 80/60, 60/40, $50 / 30$. Currently, in the University of Liège, Belgium the supply temperature is approximately around $120^{\circ} \mathrm{C}$ [22]. The conventional supply temperature in Malmö, Sweden, is between 80 and 110C [19]. For example, in Ref. [18] for the DOT of $-16 \mathrm{C}$, the average radiator system supply and return temperatures are $64 \mathrm{C}$ and $42 \mathrm{C}$, respectively. These data support the $80 / 60 \mathrm{C}$ option.

Secondly, the scenarios investigated are defined by three different design outdoor temperatures (DOTs). Accordingly, in this study nine kinds of alternative options were considered. If the predicted load is larger than the maximum heating capacity $(5200 \mathrm{~kW})$ of the DH system, an additional flow rate is used.

The performance of heat production depends on current weather conditions. To account for that, a partial load model is developed which includes the decrease of thermal production of a heating unit on system level. For each unit, a nominal load and the partial load are introduced, based on a linear approach, see Eq. 4.

Once daily heating demands were derived, taking into account the frequency of monthly outdoor temperatures and assigning each outdoor temperature a certain value based on this mechanism, a set of supply and return temperatures was obtained.

Following energy balance, the Eq. (8) is used to calculate the hot water flow through a network in case of each option.

$$
C_{e l}=c \rho G\left(\tau_{1}-\tau_{2}\right),
$$

where $c$ and $\rho$ are the specific heat and density of water at the appropriate temperature, and $\mathrm{G}$ is the water volume flow rate. When the heat consumption exceeds the capacity of the $\mathrm{DH}$ system, the required part of hot water for all the demand is provided by a network pump of a DH plant.

As a case study, a prototypical district was created based on the existing district located in Canberra, Australia. The case study represents a virtual city district that consists of one producer, five consumers and a heat network with a total length of 5,561 metres. The total heating area of the project is $128 \mathrm{~m}^{2}$ and the total designed heating load is $5.4 \mathrm{~kW}$. It was calculated with the aid of linear regression model [20] assuming excellent airtightness, levels of ceiling, floor insulation and wall insulation of $\mathrm{R} 3.5, \mathrm{R} 1$, and $\mathrm{R} 2.5$ respectively, a single glazing type and window-to-wall ratio equal to $45 \%$. The heat is generated by natural gas boilers, which are to feed the baseline heat demand of the district. Nominal efficiencies are used based on the authors' knowledge of the current practice; for the gas unit this is $90 \%$. The papers such as [25] support that assumption. Here we show an example of a bidirectional system [10]. This means the heat source translates to the heating mode when a five-day average value of outdoor temperature goes below $5 \mathrm{C}$ and turning on a cooling when the ambient goes above $20 \mathrm{C}$. The DOTs utilized in this study are $\{-3.3 ;-2.1 ;-8.7\}$ C. According to American Society of Heating, Refrigerating and Air-Conditioning Engineers (ASHRAE), the first two values represent dry-bulb temperature corresponding to the 99.6 and $99.0 \%$ annual cumulative frequency of occurrence (cold conditions), ${ }^{\circ} \mathrm{C}$. In order to analyse the energy-saving effect of the above measures for energy conservation and secondary load structure improvement, the option with a DOT of $-8.7 \mathrm{C}$ is designed to act as the benchmark. $18 \mathrm{C}$ was chosen for an indoor temperature. Due to network structure, once certain components happen to failure, the related consumers cannot obtain enough heat power, which would affect the internal status of consumers especially the indoor temperature [15].

The calculations were performed using Microsoft Excel, a commercial spreadsheet programme, and weather evaluations are based on Australian data.

Thus, the daily minimum air temperature is derived from real-life operational records for 2017 at the Canberra Airport Station [32]. It has a number of 70351, was opened in 2008 and situated within a latitude of $35.31^{\circ} \mathrm{S}$, longitude of $149.20^{\circ}$ E, 577 m elevation. 
The daily minimum air temperature is generally recorded at 9 am of local time. It is the lowest temperature for the 24 hours leading up to the observation, and it is recorded as the minimum temperature for the day on which the observation was made.

\section{Results and Discussion}

Generally, compared to the conventional energy system, although a DH system induces extra thermal losses and needs more electricity for pumping, it can offset these drawbacks through a rational plan of the urban spatial structure and the cooperation with the supply source [33].

The simulated and scheduled outlet temperatures are illustrated in Figure 2, and the relative errors are shown in Figure 3.

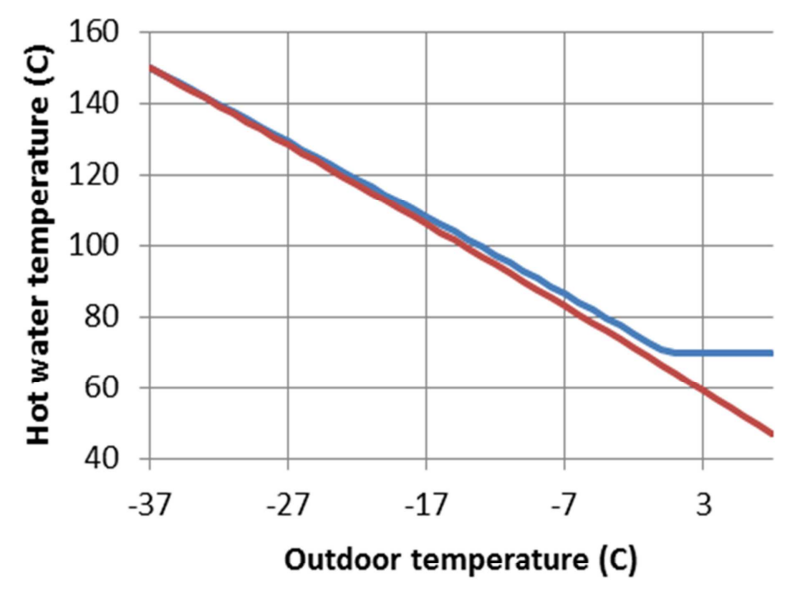

Scheduled supply temperature Ti - Simulated supply temperature $\tau 1$

Figure 2. Comparison of the actual and simulated output temperatures.



Figure 3. Validation of temperatures.

The relative errors of the simulated supply temperature $\tau_{1}$ and scheduled one $T_{i}$ are varying mostly within $\pm 5 \%$, which is in a satisfying range. It is obviously more accurate than the best error value of $11.56 \%$ obtained by heat demand forecast [16]. Therefore, a nonlinear model of the supply and return temperatures given in Eq. (1) and (2) can describe the thermal dynamics of a DH system with an appropriate accuracy.

The largest temperature error between the calculated results and predefined data is $5^{\circ} \mathrm{C}$ at the ambient temperature of $0^{\circ} \mathrm{C}$. In view of the fact that the largest error occurs once (Figure 2) and is less than $+7 \%$, the simulation results can be considered to meet the requirements of the $\mathrm{DH}$ network temperature simulation.

The temperatures within the considered year are shown in Figure 4.



Figure 4. Annual climatic chart for Canberra, Australia (2017).

The changeability of the thermal load determined as a factor of external air temperature can be described by the value of the system's duration in a particular state using experimental data obtained from the observations of normal functioning as the same with [12]. If there are no abnormal operations or large changes of outdoor temperature, remarkable variations in a relative heat load or DH network supply temperature profiles may indicate problems either in a DH system or in the measurements [34].

This study employed 9 different scheduling strategies for a DH system (Figure 5).

With this model, the operation stability of a DH system is predictable. As is conceived logical, the 10-degree set point decreases with a decreasing design outside temperature and decreasing maximal supply temperature. Besides, for an unstable operation condition of a DH system, this figure can also be used to analyse the primary factor, which results in the instability of the temperatures and tune a network controller to ensure robust stability.

The results of the generated scenarios are the partial load values which are obtained with the help of the Eq. 4 for each category, refer to Figure 6. 

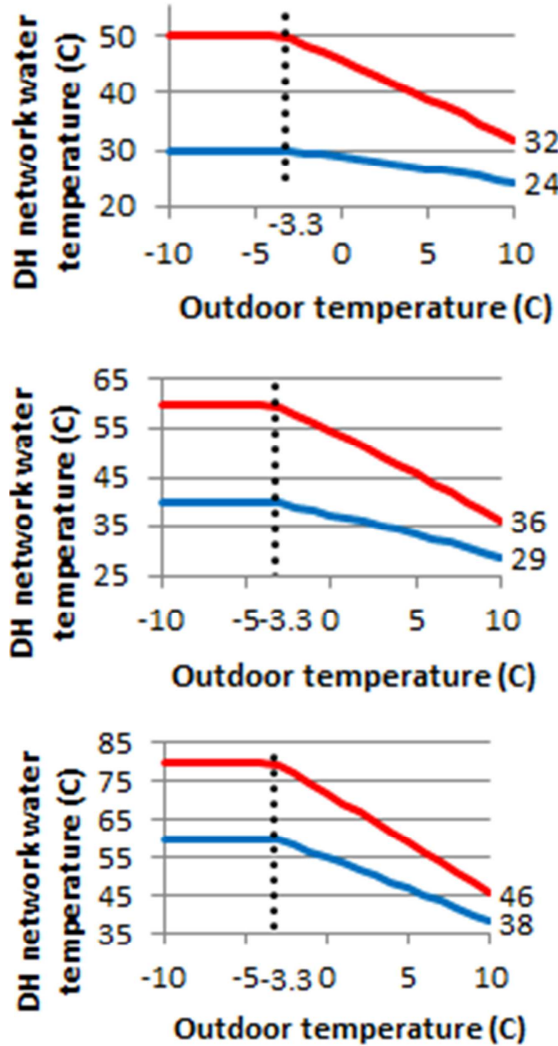

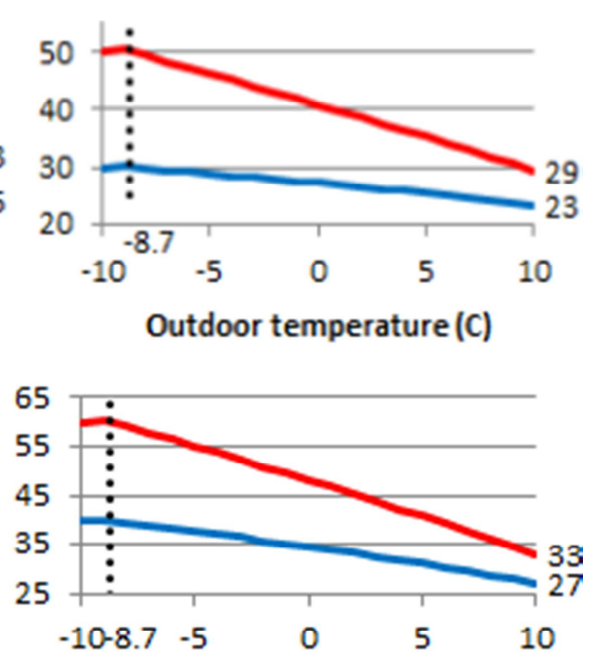

Outdoor temperature (C)

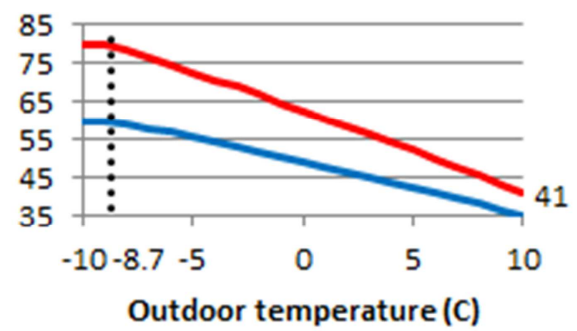

Figure 5. Supply and return temperatures depending on the ambient temperature level.

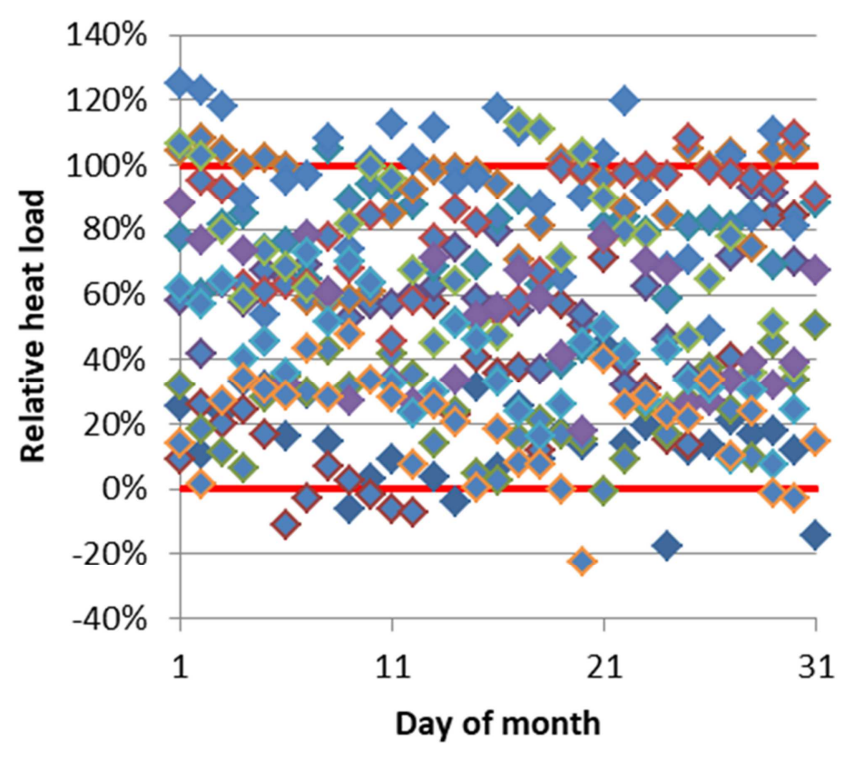

Figure 6. Total heat load.

The total, although daily, heat load for the entire network can be seen in [11]. Even though nominal efficiency is equal to about $90 \%$ for gas-fired boilers, this value decreases in partial load operation due to inflexibility and thermal losses of different kinds [25]. The load requirements are not met by the heating capacity of the DH system when the outdoor temperature decreases. This occurs when the load values exceed $100 \%$. Such an operation is possible under the condition that excess heat can be dumped at zero cost (as it is assumed in the model). The situation might be different if the part-load operation of a DH plant is implemented [24]. In Figure 6 one can also notice that cold weather causes overload in the heating system during 29 days inducing 29 peak points' occurrence. The reason why the excess heat power peaks were so large was that, despite fairly low heating demands, some heating was utilised during daytime when the temperature was below the DOT. By reducing the peak load, a smaller sizing of the different components in a thermal network is possible, thereby decreasing investment costs [4].

As it can be seen from the previously presented data, there is more than half of days when the heat output is relatively low compared with the capacity of the equipment installed in central energy plants (lower than 60\%). A number of DH plants installed in Chongqing, Shanghai, Wuhan, and other areas of China have also faced similar situations in which the actual operation load is too small [27]. However, in order to guarantee the normal operation, the actual instantaneous output of any equipment should be within the certain range [2].

An analysis of the annual behaviour can provide useful insights related to the consumption patterns of the users. In future, the effect of the hours on heat demand can be described by analysing the profile patterns of each day in detail [35].

The following step is to present supply line performance by its duration curve, as illustrated by Figure 7. 




Figure 7. Supply temperature at the DH plant side.

Figure 7 shows that the suggested solution is capable of providing the annual average supply temperature mostly in the range of $60-80 \mathrm{C}$ depending on a specific heat demand. In April and September, the values of the temperature at the outlet section of the DH plant are mostly $45 \mathrm{C}-60 \mathrm{C}$. The energy provided from a heat source to the network shows fluctuation and intermittent due to weather change.

To support the discussion of the paper, it is sufficient to provide an example of an estate located on a farmland north of Nottingham city, UK, where the supply temperature was as high as $82^{\circ} \mathrm{C}$ still guaranteeing the expected indoor comfort and avoiding unnecessary high return temperatures [8]. As is observed in [6], with the primary supply temperature increasing to a high level, the operation stability of a heating substation will be damaged, and the fluctuations will occur.

The data for the daily heating power demand were transformed into an outdoor temperature dependant power demand curve (Figure 6) that was used to compute the flow rate for each of the scenarios (Figure 8).

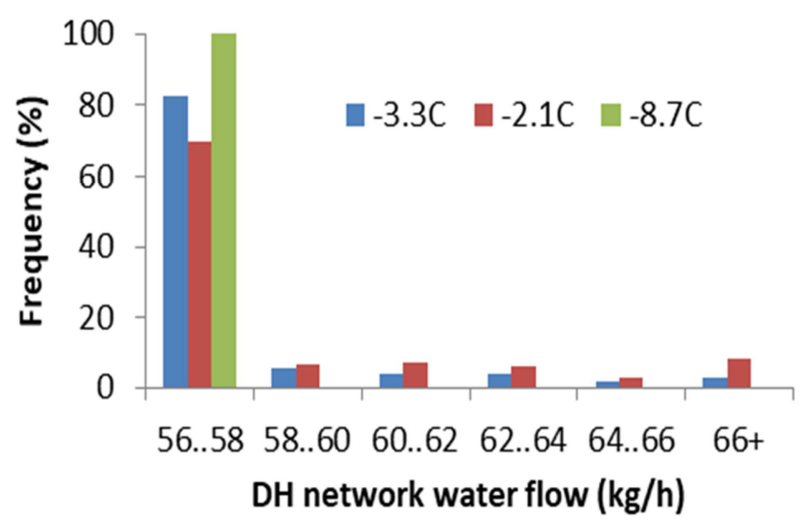

Figure 8. Frequency map as obtained for each of three DOTs.

Under the designed condition, the flow is determined by the eq. 1 and the regulation approaches are obtained. Furthermore, the water flow rate would change accordingly. The resulting flow is quite stable, ranging only from 56 to $68 \mathrm{~kg} / \mathrm{h}$. By comparison, the total flow rate of heating water in Kaunas city, Lithuania, can vary 3.9 times: from around $\sim 1,800$ to $\sim 7,000$ $\mathrm{t} / \mathrm{h}$ [14]. A control system is intended to use a distribution system to provide the heating capacity to consumers and run a pump to obtain additional flow if required. As expected from Figure 5, the mass flow increases only as the supply temperature reaches its limits of 50,60 , or $80 \mathrm{C}$. Compared to the $-2.6 \mathrm{C}$, the $-3.3 \mathrm{C}$ strategy shows a frequency of an increased flow lower by $16 \%$ corresponding to an improvement of electricity consumption for the entire DH system. The same approach is presented in [28]. In Ref. [26] the total mean DH system's demand is equal to $558 \mathrm{MW}$ requiring the total average water flow rate of $2,222 \mathrm{~kg} / \mathrm{s}$. If the flow rate requirements for circulation are low, it is possible to downsize a pipe system [23].

\section{Conclusion}

Taking into account the deficiencies of conventional evaluation for DH networks, this study modifies restrictive assumptions, especially the hypothesis of constant outdoor temperature, and analyzes the influence of outside temperature on the changeability of heat losses and electricity consumption for repairable DH networks based on the state-space method.

In this paper, the nonlinear model of supply and return temperatures was developed. In order to validate the nonlinear model of a DH system, the parameters and measured data provided in Ref. [32] were adopted in simulation.

The obtained results can be achieved without large investments in a DH system just by adjusting and controlling temperatures of a heat radiator, circulating in the network, and its flow rates.

Finally, a better understanding of consumer behaviour and response to various changes in energy systems is helpful in terms of forecasting [13].

\section{Acknowledgements}

This research was supported by the Government of the Russian Federation under Project No. 860 (August, 82017 Decree). The Author thanks the Omsk District Heating Supply Company ('Omsk RTS', JSC) for a cooperation and kindly provided information. The author would like to acknowledge the valuable comments and suggestions of the reviewers, which have improved the quality of this paper. The author also expresses gratitude to the unnamed editor who has proof-read and edited the text.

\section{References}

[1] B. J. Claessens, D. Vanhoudt, J. Desmedt, and F. Ruelens, "Model-free control of thermostatically controlled loads connected to a district heating network," Energy Build., vol. 159, pp. 1-10, Jan. 2018. 
[2] J. Hou, P. Xu, X. Lu, Z. Pang, Y. Chu, and G. Huang, "Implementation of expansion planning in existing district energy system: A case study in China," Appl. Energy, vol. 211, pp. 269-281, Feb. 2018.

[3] A. Delangle, R. S. C. Lambert, N. Shah, S. Acha, and C. N. Markides, "Modelling and optimising the marginal expansion of an existing district heating network," Energy, vol. 140, pp. 209-223, Dec. 2017.

[4] A. Vandermeulen, B. van der Heijde, and L. Helsen, "Controlling district heating and cooling networks to unlock flexibility: A review," Energy, Mar. 2018.

[5] I. del Hoyo Arce, S. Herrero López, S. López Perez, M. Rämä, K. Klobut, and J. A. Febres, "Models for fast modelling of district heating and cooling networks," Renew. Sustain. Energy Rev., vol. 82, pp. 1863-1873, Feb. 2018.

[6] Y. Wang et al., "Operation stability analysis of district heating substation from the control perspective," Energy Build., vol. 154, pp. 373-390, Nov. 2017.

[7] M. Dahl, A. Brun, and G. B. Andresen, "Using ensemble weather predictions in district heating operation and load forecasting," Appl. Energy, vol. 193, pp. 455-465, May 2017.

[8] M. Tunzi, R. Boukhanouf, H. Li, S. Svendsen, and A. Ianakiev, "Improving thermal performance of an existing UK district heat network: A case for temperature optimization," Energy Build., vol. 158, pp. 1576-1585, Jan. 2018.

[9] M. Chertkov and N. N. Novitsky, "Thermal Transients in District Heating Systems," Energy, Jan. 2018.

[10] R. Zarin Pass, M. Wetter, and M. A. Piette, "A thermodynamic analysis of a novel bidirectional district heating and cooling network," Energy, vol. 144, pp. 20-30, Feb. 2018.

[11] G. Schweiger, P.-O. Larsson, F. Magnusson, P. Lauenburg, and S. Velut, "District heating and cooling systems - Framework for Modelica-based simulation and dynamic optimization," Energy, vol. 137, pp. 566-578, Oct. 2017.

[12] B. Babiarz and A. Blokus-Roszkowska, "Probabilistic model of district heating operation process in changeable external conditions," Energy Build., vol. 103, pp. 159-165, Sep. 2015.

[13] Z. Ma et al., "The Role of Data Analysis in the Development of Intelligent Energy Networks," IEEE Netw., vol. 31, no. 5, pp. 88-95, 2017.

[14] M. Valinčius, M. Vaišnoras, and A. Kaliatka, "Study and demonstration of pressure wave-based leak detection in a district heating network," Struct. Infrastruct. Eng., vol. 14, no. 2, pp. 151-162, Feb. 2018.

[15] X. Shan, P. Wang, and W. Lu, "The reliability and availability evaluation of repairable district heating networks under changeable external conditions," Appl. Energy, vol. 203, pp. 686-695, Oct. 2017.

[16] D. Geysen, O. De Somer, C. Johansson, J. Brage, and D. Vanhoudt, "Operational thermal load forecasting in district heating networks using machine learning and expert advice," Energy Build., vol. 162, pp. 144-153, Mar. 2018.

[17] S. V. Chicherin, "Unlocking a potential of district heating network efficient operation and maintenance by minimizing the depth of a trench system," Bull. Tomsk Polytech. Univ. Geo Assets Eng., vol. 328, no. 9, pp. 49-56, 2017.
[18] M. Jangsten, J. Kensby, J.-O. Dalenbäck, and A. Trüschel, "Survey of radiator temperatures in buildings supplied by district heating," Energy, vol. 137, pp. 292-301, Oct. 2017.

[19] L. Brange, J. Englund, and P. Lauenburg, "Prosumers in district heating networks - A Swedish case study," Appl. Energy, vol. 164, pp. 492-500, Feb. 2016.

[20] N. Aghdaei, D. Daly, and T. McCarthy, "Linear regression models for prediction of annual heating and cooling demand in representative Australian residential dwellings," Energy Procedia, vol. 121, pp. 79-86, Sep. 2017.

[21] I. Andrić, J. Fournier, B. Lacarrière, O. Le Corre, and P. Ferrão, "The impact of global warming and building renovation measures on district heating system techno-economic parameters," Energy, Mar. 2018.

[22] K. Sartor, V. Lemort, and P. Dewallef, "Improved district heating network operation by the integration of high-temperature heat pumps,” Int. J. Sustain. Energy, pp. 1-15, Oct. 2017.

[23] H. Averfalk and S. Werner, "Novel low temperature heat distribution technology," Energy, vol. 145, pp. 526-539, Feb. 2018.

[24] D. Romanchenko, M. Odenberger, L. Göransson, and F. Johnsson, "Impact of electricity price fluctuations on the operation of district heating systems: A case study of district heating in Göteborg, Sweden," Appl. Energy, vol. 204, pp. 1630, Oct. 2017.

[25] S. Coss, V. Verda, and O. Le-Corre, "Multi-objective optimization of District Heating Network model and assessment of Demand Side Measures using the load deviation index," J. Clean. Prod., Feb. 2018.

[26] M. Badami, A. Fonti, A. Carpignano, and D. Grosso, "Design of district heating networks through an integrated thermo-fluid dynamics and reliability modelling approach," Energy, vol. 144, pp. 826-838, Feb. 2018.

[27] N. Deng et al., "Comparative analysis of optimal operation strategies for district heating and cooling system based on design and actual load," Appl. Energy, vol. 205, pp. 577-588, Nov. 2017.

[28] H. Wang, H. Wang, H. Zhou, and T. Zhu, "Modeling and optimization for hydraulic performance design in multi-source district heating with fluctuating renewables," Energy Convers. Manag., vol. 156, pp. 113-129, Jan. 2018.

[29] K. Sernhed, K. Lygnerud, and S. Werner, "Synthesis of Recent Swedish District Heating Research,” Energy, Mar. 2018.

[30] E. Guelpa, G. Barbero, A. Sciacovelli, and V. Verda, "Peak-shaving in district heating systems through optimal management of the thermal request of buildings," Energy, vol. 137, pp. 706-714, Oct. 2017.

[31] S. V. Chicherin, "New approach to determination of corrosion damage degree of pipeline system elements," Bull. Tomsk Polytech. Univ. Geo Assets Eng., vol. 327, no. 12, pp. 110-115, 2016.

[32] S. Chicherin, "Network temperatures and flow rate: probability of district heating in Canberra, Australia," 2018. [Online]. Available: http://dx.doi.org/10.17632/ngngkp5cwh.1.

[33] Q. Wu, H. Ren, W. Gao, P. Weng, and J. Ren, "Coupling optimization of urban spatial structure and neighborhood-scale distributed energy systems," Energy, vol. 144, pp. 472-481, Feb. 2018. 
[34] H. Wang, H. Meng, and T. Zhu, "New model for onsite heat loss state estimation of general district heating network with hourly measurements," Energy Convers. Manag., vol. 157, pp. 71-85, Feb. 2018.
[35] M. Noussan, M. Jarre, and A. Poggio, "Real operation data analysis on district heating load patterns," Energy, vol. 129, pp. 70-78, Jun. 2017. 